\title{
A New Argument for Lexical Decomposition: Transparent Readings of Verbs ${ }^{1}$
}

\author{
Seth Cable \\ University of Massachusetts, Amherst \\ University of British Columbia
}

Percus (2000) has argued that subordinate verbs do not admit of transparent (de re) readings. In this squib, I will argue that such verbs in English do admit of a kind of transparent reading. Furthermore, this particular reading suggests that, at some level of syntactic and/or semantic analysis, verbs must be decomposed into a primitive action predicate (i.e., "do") and a nominal argument describing the action performed. That is, this reading suggests that a verb like "dance" must be semantically decomposed as a complex predicate "do dancing".

In order to keep my discussion here brief, I will presuppose some familiarity with Percus (2000), as well as the kind of situation-semantic framework he assumes (cf. Kratzer 2008). In the following section, I introduce the reading of interest.

\section{A Transparent Reading of Subordinate Verbs}

Imagine the following scenario. You and I are roommates. Moreover, we have entered ourselves into a dance competition. The act that we are preparing to perform is, specifically, a tap-dance routine. Every day, at 3PM, we go to the dance studio to practice our tap-dancing.

Enter our friend Mary. Mary lives with us, and knows that we are in a dance competition. However, Mary doesn't have any idea what kind of dance we will be performing. That is, although Mary knows that we leave for the studio every day at 3PM to practice, she has no idea that we are, specifically, tap-dancing.

Now, suppose that one day, we decide to blow off practice. That is, at 3PM, we tell Mary that we're leaving to practice, but then decide at the last minute to go to the movies. Suppose that, at the theater, I turn to you and utter sentence (1a) below.

a. Mary thinks we're tap-dancing right now.

b. Mary thinks we're doing (our daily) tap-dancing right now.

My own judgment, as well as those of other English speakers I've polled, is that there is an interpretation under which sentence (1a) is true in the scenario described. Furthermore, let us also briefly note that sentence (1b) likewise possesses an interpretation under which it is true in this scenario. Finally, let us note that, for what it's worth, speakers accept (1b) as a paraphrase of the interpretation under which (1a) is true.

In a moment, we will begin to consider what kind of logical formula could represent this interpretation of (1a). Before we do, however, let us first consider a somewhat more complex case, as it will prove helpful to the development of our analysis.

Suppose now that my brother has joined our little tap-dance troupe. Suppose also that Mary knows this, and knows that he practices with us every day at 3PM. Again, though, Mary has no idea what dance we are performing. Finally, suppose that one day, my brother blows off

\footnotetext{
${ }^{1}$ I wish to thank Michael Barrie, Lisa Matthewson, Andrew McKenzie, Hotze Rullmann, and Tamina Stephenson. I also gratefully acknowledge the support of the Killam Trusts, who supported this research through a Killam Postdoctoral Research Fellowship.
} 
practice. That is, he arrives at our apartment, tells Mary that we're all going off to practice, but then at the last moment goes to the movies instead. Now suppose that at the dance studio, you mistakenly remark that Mary might be mad at my brother for going to the movies without her. As a correction, I utter the sentence in $(2 a)$.

(2) a. Mary thinks my brother is tap-dancing right now.

b. Mary thinks my brother is doing (his daily) tap-dancing right now.

Again, the judgment from English speakers seems to be that (2a) is both natural and true in the scenario described. Furthermore, this is again paralleled by the sentence in (2b), which is also true in this scenario, and which speakers accept as a kind of paraphrase of their interpretation of (2a).

\section{Characterizing the Reading}

Let us, then, consider what kind of logical formula could represent this reading of $(2 a){ }^{2}{ }^{2}$ First of all, we can rule out the formula below. ${ }^{3}$

$$
\left.\operatorname{think}\left(\mathrm{s}_{0}, \text { Mary },[\lambda \mathrm{s} . \text { tap-dance( } \mathrm{s}, \text { my-brother(s) })\right]\right)
$$

This formula represents a simple, purely opaque reading of sentence (2a). According to this formula, in all situations $s$ consistent with Mary's beliefs, my brother in $s$ is tap-dancing. In the scenario described, however, this formula would be false, as Mary entertains no beliefs regarding what dance my brother is performing. In some of her belief-situations, he is tap-dancing, but in others he is waltzing, or even break-dancing.

Since the targeted reading of (2a) does not impute knowledge of my brother's tap-dancing to Mary, we might consider the formula in (4) below. Within this formula, the predicate tapdance is evaluated, not in Mary's belief-situations, but in the real (or topical) situation.

$$
\operatorname{think}\left(\mathrm{s}_{0}, \text { Mary },\left[\lambda \mathrm{s} . \operatorname{tap}-\operatorname{dance}\left(\mathrm{s}_{0}, \text { my-brother(s) }\right]\right)\right.
$$

As discussed at length by Percus (2000), the formula in (4) would represent a transparent interpretation of the verb 'tap-dance'. However, it is not the reading that we observe for sentence (2a). Indeed, as noted by Percus, (4) doesn't seem to be a possible reading of sentence (2a). Roughly speaking, (4) states that all of Mary's belief situations $s$ are such that some tap-tap dancer in the real world $\mathrm{s}_{0}$ is my brother in $s$. Clearly, even if such a reading of (2a) existed, it would not be true in the imagined scenario.

2 The reader is invited to confirm that sentences structurally parallel to (1a) and (2a) can also be observed to have this reading. For example, Hotze Rullmann (p.c.) notes that (i) below is both true and natural in a scenario where Mary knows only that we exercise every morning, and not that we specifically go running.

(i) Mary thinks that we are running right now.

Similarly, Andrew McKenzie (p.c.) notes that (ii) can be true in a scenario where Mary knows only that we work together, and not that we work, specifically, at a burger joint.

(ii) Mary thinks we're flipping burgers right now.

${ }^{3}$ I will ignore the temporal adverbial right now in sentences (1a) and (2a). I will also ignore the indexicality of the subordinate subject. 
So how could we represent the targeted readings of (1a) and (2a)? Let us for a moment reflect on the fact that sentences (1b) and (2b), which are also true in the imagined scenarios, are accepted by speakers as paraphrases of the intended readings of (1a) and (2a). Sentence (2b) is repeated below.

$$
\text { Mary thinks my brother is doing (his daily) tap-dancing right now. }
$$

Interestingly, given its syntactic structure, it is actually rather unsurprising that (5) can be true in scenarios where Mary doesn't know the exact nature of my brother's daily activity. After all, that information is conveyed in (5) by the direct object DP 'tap-dancing', and we would certainly predict a reading whereby that DP is interpreted transparently. Simplifying somewhat, a transparent interpretation of the DP tap-dancing in (5) would yield the logical formula in (6).

$$
\operatorname{think}\left(\mathrm{s}_{0}, \operatorname{Mary},\left[\lambda \mathrm{s} . \exists \mathrm{x} . \operatorname{do}(\mathrm{s}, \mathrm{my}-\operatorname{brother}(\mathrm{s}), \mathrm{x}) \& \operatorname{tap}-\operatorname{dancing}\left(\mathrm{x}, \mathrm{s}_{0}\right)\right]\right)
$$

This formula states that in all of Mary's belief situations $s$, there is some activity $\mathrm{x}$ such that my brother in $s$ is doing $\mathrm{x}$ in $s$, and $\mathrm{x}$ in the real world is tap-dancing. Importantly, this formula would be true in the imagined scenario for $(2 a, b)$. In that scenario, Mary's beliefs entail that my brother performing some activity. Moreover, it is also true that, in the actual world, the activity that Mary thinks my brother is doing is tap-dancing. Finally, this formula would allow that Mary's belief situations are not all ones where the activity my brother is doing is tap-dancing. In some of her belief situations, that activity might be square-dancing, or break-dancing.

For these reasons, the formula in (6) would be true in the scenario sketched for $(2 \mathrm{a}, \mathrm{b})$, and we therefore predict that $(2 \mathrm{~b})$ should be interpretable as true in that scenario. Now, let us return to sentence (2a). We've already seen that the logical representations in (3) and (4) cannot capture the reading whereby it is true in our constructed scenario. However, we've also seen that the formula in (6) can capture this reading; unlike (3) and (4), formula (6) is true in the scenario sketched for (2a). Since it is the only candidate formula which has this property, I will propose that (6) also represents the targeted true reading of sentence (2a). This proposal would additionally capture the fact that native speakers perceive sentence (2b) to be a paraphrase of the interpretation where $(2 a)$ is true.

I therefore conclude that (modulo certain simplifications) (6) represents the targeted reading of (2a). Thus, $(6)$ is a possible reading for $(2 a)$.

\section{Consequences for Percus's (2000) Theory of Binding}

Thus far, this squib has focused on demonstrating that (6) is a possible reading for (2a). Taking this as granted, I will now explore a few consequences and questions following from this analysis.

First, let us consider how this analysis impacts Percus's (2000) generalization that verbs do not possess transparent readings. Given the impossibility of readings like (4), Percus (2000) proposes the following generalization.

(7) Generalization $\mathbf{X}$ : The situation pronoun that a verb selects for must be co-indexed with the nearest $\lambda$ above it. 
This condition would clearly rule out readings like (4), given that they would have to be derived from structures like (8) below. In such structures, the situation pronoun selected by the verb is not bound by the lambda introduced in the $\mathrm{CP}$ of the subordinate clause.

$$
\text { [ Mary thinks [CP } \boldsymbol{\lambda} \mathbf{s}_{\mathbf{1}} \text { [IP [DP } \mathbf{s}_{\mathbf{1}} \text { my brother ] [VP } \mathbf{s}_{\mathbf{0}} \text { is tap dancing ] ] ] }
$$

Interestingly, however, (7) would not rule out structures like that in (9) below.

$$
\text { [ Mary thinks [CP } \boldsymbol{\lambda} \mathbf{s}_{\mathbf{1}} \text { [IP [DP } \mathbf{s}_{\mathbf{1}} \text { my brother ] [VP } \mathbf{s}_{\mathbf{1}} \text { do [DP } \mathbf{s}_{\mathbf{0}} \text { tap-dancing ] ] ] ] }
$$

This structure, which is assigned the targeted reading of (2b), is in accordance with (7), as the situation pronoun selected by the main verb 'do' is bound by the nearest lambda. Only the situation pronoun selected by the nominal complement 'tap-dancing' is non-locally bound. Thus, (7) would correctly predict that (6) is a possible interpretation of (2b).

Now consider the fact that sentence (2a) also possesses the interpretation in (6). Would this fact challenge the generalization in (7)? It indeed would, if the sentence possessed the structure in (8) at the relevant level of syntactic representation (i.e., LF). On the other hand, Percus's generalization would remain intact if such sentences actually possessed a structure akin to (9), where the subordinate verb is a simple action predicate ('do'), and the predicate describing the nature of the action performed is a separate phrase possessing its own distinct situation argument. Note, furthermore, that such a structural analysis would be the simplest (and perhaps only) means of assigning sentence (2a) the observed reading in (6).

I conclude, then, that the availability of (6) as a reading for (2a) needn't upset Percus's generalization in (7). In order to derive such a reading for (2a), one must posit a structural analysis that would ultimately satisfy the condition in (7). Furthermore, even if it were somehow possible for the reading in (6) to be assigned to the structure in (8), such an analysis could still be said to preserve the 'spirit' of Percus's generalization, which has been characterized as 'verbs do not admit of transparent readings' (Keshet 2008). After all, the readings which Percus seeks to exclude, such as (4), are ones where no part of subordinate verb's meaning is evaluated is the matrix subject's belief situations. Even under reading (6), however, Mary's beliefs must include the information that the action denoted by the subordinate verb takes place. It is only the nature of the action, the way in which the action is described, that can be evaluated in the actual world/situation.

Thus, the ability for (2a) to receive the interpretation in (6) is entirely consistent with the original observations and generalizations of Percus (2000).

\section{Some Brief Conceptual and Empirical Questions}

In this section, I will briefly consider some outstanding questions, both empirical and conceptual, that our analysis faces. I will not answer these questions here, but instead raise them for future research.

Despite its advantages over the relevant alternatives, there are a number of ways in which the formula in (6) is a drastic simplification of the targeted reading of (2a,b), and fails to capture the full content of this reading. For example, one question not addressed in our present discussion is "what kinds of things do predicates like '[ $\lambda \mathrm{x}$. tap-dancing $\left.\left(\mathrm{x}, \mathrm{s}_{0}\right)\right]$ ' hold of?" This question is made especially difficult by the fact that, in the scenario validating the targeted 
reading, this predicate is presumably true of some real-world entity $\mathrm{x}$, even though the subordinate subject isn't actually tap-dancing.

One possibility worth considering is that in sentences like $(1 a, b)$ and $(2 a, b)$, predicates like ' $\left[\lambda x\right.$. tap-dancing $\left.\left(x, s_{0}\right)\right]$ ' denote a set of 'habits'. This would accord both with the fact that no actual 'tap dancing' occurs in the imagined scenario, as well as the fact that 'habituality' of some sort seems to be a necessary condition for the truth of the targeted reading. In all cases I've examined thus far, the targeted reading is only true if the subordinate subject has a habit of doing the action described by the subordinate verb. If this assumption is dropped, then sentences like (1a) and (2a) are necessarily false.

Besides this condition of 'habituality', our formula in (6) fails to capture certain key conditions that the targeted reading places upon the knowledge of the matrix subject. ${ }^{4}$ For example, in all the cases I've examined so far, the targeted reading can only be true if the matrix subject is assumed to have some information regarding the activities of the subordinate subject. That is, if Mary is assumed to know nothing about what you and I do every afternoon at 3PM only that we mysteriously leave every day at that time - then, sentence (1a) is necessarily false. However, at the other extreme, the matrix subject also cannot have false beliefs about the activities of the subordinate subject. If, for example, Mary is assumed to falsely believe that you and I are practicing a break-dancing routine, then sentence (1a) is again necessarily false.

These issues demonstrate that our analysis in (6) fails to capture several key and highly interesting features of the targeted reading of (1a) and (2a). However, it is also nevertheless clear that any more complete analysis of this reading will still have to preserve that aspect of (6) which is of most interest to us here: the subordinate verb must be decomposed into a complex predicate akin to 'do (his daily) tap-dancing'.

\section{Conclusion}

In this squib, I have argued that there is a previously undocumented 'transparent' reading for sentence (10a), and that given the available candidates, this reading is best represented via formula (10b).

(10) a. Mary thinks my brother is tap-dancing right now.

b. $\operatorname{think}\left(\mathrm{s}_{0}, \operatorname{Mary},\left[\lambda \mathrm{s} . \exists \mathrm{x} . \operatorname{do}(\mathrm{s}, \operatorname{my}-\operatorname{brother}(\mathrm{s}), \mathrm{x}) \& \operatorname{tap}-\operatorname{dancing}\left(\mathrm{x}, \mathrm{s}_{0}\right)\right]\right)$

We've also seen that the analysis in (10b) raises a number of questions, both empirical and conceptual. Despite these areas of concern, I conclude that (10b) is basically 'on the right track', and for all intents and purposes accurately characterizes a possible reading for (10a). That is, however the account is ultimately to be fleshed out, sentences like (10a) admit of a reading with the following core properties: (a) the matrix subject's belief worlds are all ones where the act described by the subordinate verb is performed, but (b) the way in which the subordinate verb characterizes that act is evaluated in the real world.

In closing, let us consider the consequences that the reading in (10b) might hold for our theory of the syntax and semantics of verbs. Of course, the analysis in (10b) has a rather obvious semantic consequence: we must conclude that, semantically, a verbal head like tap-dance represents the complex predicate do tap-dancing. More concretely, we must assume that the

\footnotetext{
${ }^{4}$ I thank Michael Barrie and Hotze Rullmann for first bringing these points to my attention.
} 
meaning of a verb like tap-dance is composed of two more primitive predicates: (i) a predicate expressing that a given act $\mathrm{x}$ has been accomplished in a situation $\mathrm{s}$ (e.g. do), and (ii) a separate predicate expressing that a given act $\mathrm{x}$ is of a particular type in a situation $\mathrm{s}$ (e.g. tap-dancing).

This semantic consequence, in turn, converges with well-known morpho-syntactic evidence that a verb like tap-dance is syntactically derived from a more complex structure, one that is akin to a complex predicate like do tap-dancing (inter alia, Hale \& Keyser 1993, Kratzer 1996). Despite these prior results, the claim that simple verbs like tap-dance are, at a greater level of abstraction, semantically and syntactically complex remains controversial (Fodor \& Lepore 1999, Horvath \& Siloni 2002). The fact that sentences like (10a) must be seen as having readings akin to $(10 \mathrm{~b})$ provides some novel, additional support for this now popular, though still controversial, claim.

\section{References}

Fodor, J. and E. Lepore (1999) "Impossible Words.” Linguistic Inquiry 30:3. pp. 445 - 453. Hale, K. and J. Keyser (1993) "On Argument Structure and the Lexical Expression of Syntactic Relations." In Hale, K. and J. Keyser (eds.) The View from Building 20. MIT

Press. Cambridge, MA.

Horvath, J. and T. Siloni (2002) "Against the Little-v Hypothesis." Rivista di Grammatica Generativa 27. pp. $107-122$.

Keshet, E. (2008) "Only the Strong: Restricting Situation Variables." Talk presented at SALT 18. Manuscript. MIT. Cambridge, MA.

Kratzer, A. (1996) "Severing the External Argument from its Verb." In Rooryck, J. and L. Zaring (eds) Phrase Structure and the Lexicon. Kluwer. Dordrecht.

Kratzer, A. (2008) "Situations in Natural Language Semantics." In Zalta, E. (ed) The Stanford Encyclopedia of Philosophy (Spring 2008 Edition). Available at: http://plato.stanford.edu/archives/spr2008/entries/situations-semantics/

Percus, O. (2000) "Constraints on Some Other Variables in Syntax." Natural Language Semantics 8:3. pp. $173-229$. 